\title{
The Diverse Bacterial Community in Intertidal, Anaerobic Sediments at Sapelo Island, Georgia
}

\author{
Chris Lasher • Glen Dyszynski • Karin Everett • \\ Jennifer Edmonds • Wenying Ye • Wade Sheldon • \\ Shiyao Wang • Samantha B. Joye • Mary Ann Moran • \\ William B. Whitman
}

Received: 29 October 2008 / Accepted: 5 December 2008 / Published online: 11 February 2009

(C) The Author(s) 2009. This article is published with open access at Springerlink.com

\begin{abstract}
The phylogenetic diversity and composition of the bacterial community in anaerobic sediments from Sapelo Island, GA, USA were examined using 16S rRNA gene libraries. The diversity of this community was comparable to that of soil, and 1,186 clones formed 817 OTUs at $99 \%$ sequence similarity. Chaol estimators for the total richness were also high, at 3,290 OTUs at 99\% sequence similarity. The program RDPquery was developed to assign clones to taxonomic groups based upon comparisons to the RDP database. While most clones could be assigned to describe phyla, fewer than $30 \%$ of the clones could be assigned to a described order. Similarly, nearly $25 \%$ of the clones were only distantly related ( $<90 \%$ sequence similarity) to other environmental clones, illustrating the unique composition of this community. One quarter of the clones were related to one or more undescribed orders within the $\gamma$-Proteobacteria. Other
\end{abstract}

Electronic supplementary material The online version of this article (doi:10.1007/s00248-008-9481-9) contains supplementary material, which is available to authorized users.

C. Lasher · G. Dyszynski $\cdot$ K. Everett $\cdot$ S. Wang $\cdot$

W. B. Whitman $(\square)$

Department of Microbiology, University of Georgia,

Athens, GA 30602-2605, USA

e-mail: whitman@uga.edu

J. Edmonds $\cdot$ W. Ye $\cdot$ W. Sheldon $\cdot$ S. B. Joye $\cdot$ M. A. Moran

Department of Marine Sciences, University of Georgia,

Athens, GA 30605, USA

Present address:

C. Lasher

Virginia Bioinformatics Institute, Virginia Tech,

Blacksburg, VA 24061, USA

Present address:

G. Dyszynski

2521 Piedmont Rd NE \#2427,

Atlanta, GA 30324, USA abundant groups included the $\delta$-Proteobacteria, Bacteroidetes, and Cyanobacteria. While these phyla were abundant in other estuarine sediments, the specific members at Sapelo Island appeared to be different from those previously described in other locations, suggesting that great diversity exists between as well as within estuarine intertidal sediments. In spite of the large differences in pore water chemistry with season and depth, differences in the bacterial community were modest over the temporal and spatial scales examined and generally restricted to only certain taxa.

\section{Introduction}

Salt marshes are among the most productive ecosystems known and vital components of the coastal marine

Present address:

K. Everett

6006 172nd Place SW,

Lynnwood 98037, USA

Present address:

J. Edmonds

Department of Biological Sciences, University of Alabama,

P.O. Box 870206, Tuscaloosa, AL 35487, USA

Present address:

W. Ye

Synthetic Genomics, Inc.,

La Jolla, CA 92037, USA 
landscape [42]. They sequester enormous amounts of carbon and act as a significant negative feedback for global increases in atmospheric carbon and warming [9, 23]. In addition, they are important sources of inorganic carbon to adjacent coastal waters [7, 58]. On the east coast of the United States, salt marshes are dominated by virtual monocultures of the cord grass Spartina alterniflora. Sediments are anaerobic, and sulfate reduction is the dominant respiration [e.g., 31]. However, iron reduction, denitrification, and aerobic respiration are all significant processes as well [17, 29, 34]. In spite of the detailed geochemical studies of these sediments, the microbial community is poorly understood. For instance, while the distribution of sulfate-reducing bacteria and methaneproducing archaea has been extensively studied, little is known about the remainder of the community.

Although a variety of methods are available to assess the prokaryotic composition and diversity of nucleic acids from environmental samples, sequencing of polymerase chain reaction (PCR) libraries of environmental rRNA genes was chosen for these studies. An important reason for this choice is that the sequences of rRNA genes provide an unequivocal identification of the organism. Even though the value of this identification depends somewhat on whether a related isolate has been characterized and the particular phylogenetic group, in many cases, it allows one to access information on the ecology, bacteriology, and physiology of related organisms. A second advantage of sequence libraries is that the results can be archived electronically and compared to libraries prepared at any future time and at any site. Thus, libraries have the potential to provide a permanent record of an organism's distribution. This type of record, which is common in eukaryotic biology, is sorely missing in prokaryotic biology. Even when a ribotype is otherwise uncharacterized, its distribution can be used to generate hypotheses concerning its function. A third advantage is that rRNA libraries enable other methodologies. Once the abundant ribotypes at a site are known, it is possible to utilize other methods to examine a wide range of specific questions. For instance, from library sequences, it is possible to design probes for fluorescence in situ hybridization (FISH) or primers for quantitative PCR. Lastly, the high efficiencies of many cloning vectors allow libraries to be prepared at a low PCR cycle number. Thus, they are less prone to many of the PCR artifacts associated with high cycle number techniques.

\section{Methods}

Sampling and geochemical analyses Duplicate cores were taken from intertidal sediment at Dean Creek on January
24, 2002 and August 1, 2002. Dean Creek Marsh is a Georgia Coastal Ecosystems Long Term Ecological Research and a Sapelo Island Microbial Observatory (SIMO) sampling area and typical of southeastern US salt marshes [8]. Sediment pore water samples were obtained using pore water diffusion equilibration samplers [22] that were manufactured, deployed, and sampled according to Weston et al. [59]. Briefly, duplicate pore water samplers filled with anoxic (helium-purged) deionized water were deployed in the intertidal creek-bank sediments 6 to 8 weeks before sampling. Sediment cores for clone library development were collected adjacent to the pore water samplers when the samplers were retrieved. Pore water samplers were processed in a helium-purged glove bag. The water in each chamber of the pore water sampler was removed using a syringe, split, and preserved for determination of ammonium $\left(\mathrm{NH}_{4}^{+}\right)$, phosphate $\left(\mathrm{PO}_{4}^{3-}\right)$, dissolved organic carbon (DOC) and nitrogen (DON), dissolved inorganic carbon (DIC), hydrogen sulfide $\left(\mathrm{H}_{2} \mathrm{~S}\right)$, sulfate $\left(\mathrm{SO}_{4}^{2-}\right)$, reduced iron $\left(\mathrm{Fe}^{2+}\right)$, and methane $\left(\mathrm{CH}_{4}\right)$ concentrations. Details of sample preservation protocols and analytical methods are provided in Weston et al. [59]. Inventories of the abovenoted constituents in top $(0-8 \mathrm{~cm})$ and bottom $(12-20 \mathrm{~cm})$ sediments were obtained by trapezoidal integration of concentrations over depth, followed by a correction for

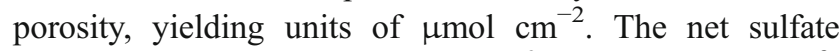
consumption, in units of $\mu \mathrm{mol}$ of $\mathrm{SO}_{4}^{2-}$ ( $\mathrm{cm}$ of sediment $)^{-2}$, was estimated by subtracting the measured sulfate inventory from the predicted sulfate inventory, which was calculated by dividing the chloride inventory by the ratio of chloride to sulfate in sea water [19, 33, 59]. Net sulfate consumption is a good proxy for the net sulfate reduction rate [59]. DIC inventories were corrected for background (overlying water) DIC concentration so that the inventory reflected DIC produced during the oxidation of organic carbon.

Preparation of Clone Libraries and Sequencing After collection, the sediment cores were stored at $-20^{\circ} \mathrm{C}$. Upon defrosting in the laboratory, the cores were sliced into $1-\mathrm{cm}$ portions, which were transferred to sterilized 50-ml Falcon tubes and stored at $-80^{\circ} \mathrm{C}$. Upon thawing, each sample was mixed well, and the bacterial community DNA was extracted from approximately $10 \mathrm{~g}$ of sediment using the MoBio Ultraclean Soil DNA MegaPrep kit (Mo Bio, Carlsbad, CA, USA). Extracted DNA was diluted to approximately $100 \mathrm{ng} /$ $\mu$ l. DNA concentrations were measured by their absorbance at $260 \mathrm{~nm}$, and DNA samples were stored at $-80^{\circ} \mathrm{C}$. A $15-$ cycle PCR was then performed on each extraction using $1 \mu \mathrm{l}$ of community DNA, $1 \mu \mathrm{l}$ of $27 \mathrm{f}$ universal primer $(10 \mu \mathrm{M}$, 5'-AGA GTT TGA TCM TGG CTC AG-3'), $1 \mu$ l of 1,492r universal primer $\left(10 \mu \mathrm{M}, 5^{\prime}\right.$-GGT TAC CTT GTT ACG ACT T-3'), $22 \mu \mathrm{l}$ of distilled water and 1 puReTaq Ready- 
To-Go PCR Bead (Amersham Pharmecia Biotech, Piscataway, NJ, USA). PCR was performed on an Eppendorf Master Cycler (Brinkman, Westbury, NY, USA) under the following conditions: $5 \mathrm{~min}$ at $95^{\circ} \mathrm{C}, 15$ cycles of $45 \mathrm{~s}$ at $95^{\circ}$ C, $30 \mathrm{~s}$ at $62^{\circ} \mathrm{C}$, and 60 or $120 \mathrm{~s}$ at $72^{\circ} \mathrm{C}$, followed by $4 \mathrm{~min}$ at $72^{\circ} \mathrm{C}$. Ligation and transformation into TOP10 chemically competent Escherichia coli cells was then performed using $4 \mu \mathrm{l}$ of PCR product and the TOPO TA Cloning Kit with pCR2.1-TOPO vector (Invitrogen, Carlsbad, CA, USA), following the manufacturer's protocol. The maximum suggested times for the ligation ( $30 \mathrm{~min}$ at room temperature) and the transformation ( $30 \mathrm{~min}$ on ice) were used. The transformation was performed using all $6 \mu \mathrm{l}$ of the ligation reaction solution. After spreading onto LB plates with $10 \mathrm{mg} / \mathrm{l}$ of kanamycin, $100 \mathrm{mg} / \mathrm{l}$ of ampicillin, and $80 \mathrm{mg} /$ 1 of X-gal, the plates were incubated overnight at $37^{\circ} \mathrm{C}$ and then stored at $4{ }^{\circ} \mathrm{C}$ for at least $24 \mathrm{~h}$. White colonies were then picked into 96-well culture blocks containing $1 \mathrm{ml}$ of freezing medium (Luria-Bertani broth with $10 \%(\mathrm{v} / \mathrm{v})$ anhydrous glycerol, $12.5 \mathrm{mg} / 1$ Kanamycin, $25.0 \mathrm{mg} / \mathrm{l}$ Ampicillin) per well. The blocks were incubated at $37^{\circ} \mathrm{C}$ for $12 \mathrm{~h}$, and $100 \mu \mathrm{l}$ per well was transferred to 96-well microtitration plates, which were then sealed with aluminum foil seal tape (Corning No. 6570) and covered with plastic lids (Corning No. 3098) to protect the seal during storage and shipping. The culture blocks and microtitration plates were stored in $-80^{\circ} \mathrm{C}$. The microtitration plates were shipped to SeqWright (Houston, TX, USA) on dry ice for sequencing.

Sequence Analysis Following trimming and editing with ChromasPro (Technylesium, Tewantin, Queensland, Australia), sequences possessed an average length of $580 \mathrm{bp}$ (range 440 to $780 \mathrm{bp}$ ). They were then aligned using PILEUP from the Wisconsin Package v. 10.2 (Genetics Computer Group, Madison, WI, USA). Alignments of greater than 400 sequences were performed in ClustalW [56]. The alignments were then edited in GeneDoc [41] to remove large insertions and deletions. For LIBSHIFF analyses and calculation of the diversity indices, the alignments were cropped to include only positions $81-459$ (E. coli numbering). In addition, regions with less than $50 \%$ sequence similarity were also masked for the phylogenetic analyses. Although this strategy reduced the number of positions analyzed, it was found to be effective in identifying the relationships among the genus-level clades. LIBSHUFF v.1.2 was performed as described by Singleton et al. [52]. Distance matrices were calculated by DNADIST of the PHYLIP 3.62 package (http://evolution.genetics.washington. edu/phylip.html) using the Jukes-Cantor correction. For the diversity indices, groups were generated from the distance matrices using a Perl script written by one of us (C.D.L.) for that purpose. The Shannon diversity and evenness indices were calculated as described by Shannon and Weaver [50].
Coverage was calculated as described by Good [20]. The Chaol estimator and its confidence intervals were calculated with SPADE. Rarefaction curves were calculated with DOTUR using the average neighbor option [49]. The average neighbor option was chosen because it yielded results most consistent with phylogenetic analyses using the neighbor-joining and the Fitch-Margoliash algorithms. Phylogenetic trees were calculated using the SEQBOOT, NEIGHBOR or FITCH, and CONSENSE programs in PHYLIP 3.62. Final trees were edited with ATV [60] and TreeExplorer ([32]; http://www.megasoftware.net/index. $\mathrm{html})$. Sequences were deposited in GenBank with accession numbers AY710525-AY710959 and AY711019-AY711876.

Additional statistical analyses were performed from BrayCurtis similarity matrixes [18, 37], which were generated from the abundances of each of the OTUs identified by DOTUR at $d=0.05$. There were 407 OTUs in the entire dataset, including 48, 46, 48, 93, 56, 3, and 133 OTUs for the Bacteriodetes, $\alpha$-Proteobacteria, $\delta$-Proteobacteria, $\gamma$ Proteobacteria, unclassified Proteobacteria, Cyanobacteria, and all other unclassified bacteria, respectively. The analyses were performed with each core as one of two replicates, and the top $(0-5 \mathrm{~cm})$ and bottom $(12-16 \mathrm{~cm})$ depths were pooled within each season. Differences in community composition among the groups were visualized using nonmetric multidimensional scaling (MDS) of the similarity matrix to produce a two-dimensional ordination figure [11]. Using untransformed Bray-Curtis similarity matrices, we performed a series of non-parametric two-way nested analysis of similarity (ANOSIM) to test whether there were significant differences in microbial community composition with depth and between seasons for the entire dataset and its subsets [12]. Variation in nine pore water chemistry variables $\left(\mathrm{pH}, \mathrm{NH}_{4}\right.$, $\mathrm{NO}_{X}$, total dissolved phosphate, DOC, $\mathrm{H}_{2} \mathrm{~S}, \mathrm{Fe}^{2+}, \mathrm{SO}_{4}^{2-}$, salinity) collected at the same sites was correlated with differences in community composition with the statistical software BVSTEP [13]. First, the program generates a similarity matrix based on normalized Euclidean distances for each environmental variable and selects the variable giving the highest Spearman rank correlation coefficient with the Bray-Curtis similarity matrix. Each remaining environmental variable is then added, and the one that improves the correlation most is retained in the model. Forward selection is continued until there is no increase in the correlation coefficient beyond a threshold value ( 0.05 for our dataset). All analyses involving the Bray-Curtis similarity values were performed with the PRIMER 5 for Windows software using the subroutines MDS, ANOSIM, and BVSTEP.

Taxonomic assignments Clones were assigned to taxonomic groups using a Java application we developed for retrieving taxonomic identifications for $16 \mathrm{~S}$ rRNA prokaryotic gene sequences (RDPquery, which is available at http://simo. 
marsci.uga.edu/public_db/rdp_query.htm). The general strategy used was as follows. For each query sequence, RDPquery obtained the ten entries with the highest Sab values from the Ribosomal Database Project or RDP (http:// rdp.cme.msu.edu) [14]. However, the sequence with the highest Sab value was frequently not the sequence with the highest similarity, in the same way that the sequence with the highest BLAST score frequently does not have the highest similarity. For instance, preliminary tests indicated that the sequence with the highest $\mathrm{Sab}$ value also possessed the highest sequence similarity only $49 \%$ of the time. However, the sequence with the highest similarity was within the ten highest Sab values $99 \%$ of the time. Therefore, it was necessary to test a range of sequences with high Sab values to find the one with the highest sequence similarity. RDPquery calculated the sequence similarity for each of the sequences with high Sab values and then identified the sequence with the highest similarity. It then created an output file with two sets of taxonomic identifications. The first set contained all the taxonomic data provided by RDP for the sequence with the highest similarity. The second set contained only those taxonomic identifications where the similarity value exceeded predetermined cutoffs. These cutoffs were generated by a survey of the taxonomy in Bergey's Manual of Systematic Bacteriology [19] and comparisons of sequences of representative taxa in the RDP database (version 8.1). The default cutoff values were set to represent the similarity values which included $95 \%$ of the comparisons for a given taxonomic level (Fig. 1). For instance, $95 \%$ of the comparisons surveyed between members of different genera from within the same family possessed less than $95 \%$ sequence similarity. Similarly, $95 \%$ of the comparisons between members of different families from within the same order possessed less than $92 \%$ sequence similarity. Thus, a clone possessing $94 \%$ sequence similarity to a type strain would be classified in the same family but not in the same genus. In this way, the guidelines were conservative and tended to assign clones to taxonomic groups when there was a high level of confidence. Subsequent analyses indicated that these phylum and class assignments were identical to those of Greengenes [15], which was not available at the time of these analyses.

\section{Results}

Biogeochemistry of the Samples As part of the SIMO, duplicate cores were collected from Dean Creek on Sapelo Island, GA, USA, in January and August 2002. The site was a small mud bar on the bank of a tidal creek in which pore water diffusion samplers had been deployed $6-8$ weeks prior to sampling [59]. A photograph of the site is included in the supplemental materials (Electronic Supplementay

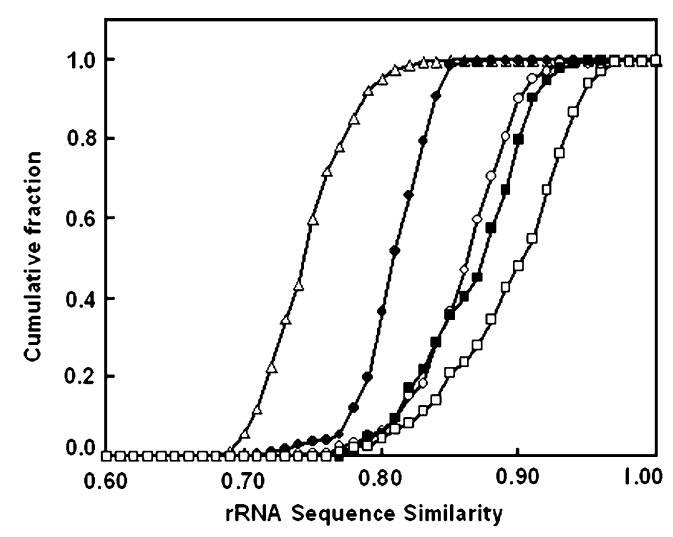

Fig. 1 Survey of taxonomic assignments in Bergey's Manual of Systematic Bacteriology [19]. At each level, the rRNA sequence similarity was determined for representatives of different taxa from within the same higher taxonomic group. Thus, at the genus level, representatives of genera within the same family were compared. At the family level, representatives within the same order were compared. All sequences used were from type strains and $>1,300 \mathrm{bp}$. No more than six sequences were selected from any one taxon. In total, the 223 genera comparisons (empty square) included representatives of 18 families, the 104 family comparisons (filled square) included representatives of five orders, the 151 order comparisons (empty circle) included representatives of seven classes, the 335 class comparisons (filled circle) included representatives of 2 phyla, and the 210 phyla comparisons (empty triangle) were all taken from the bacterial domain. The similarity values that exceeded $95 \%$ of all comparisons at each taxonomic level were: genus, 0.95; family, 0.92; order, 0.91; class, 0.85; and phylum, 0.80. Similarity is defined as the fraction of identical positions divided by the number of positions compared

Material, Fig. S1). Although free of macrophytes, benthic microalgae were present, and the upper $2 \mathrm{~mm}$ of sediments were oxic. In addition, the sediment was heavily infiltrated by fiddler crab (Uca pugnax) burrows.

Below the surface, varying amounts of the end products of microbial anaerobic respiration accumulated. Seasonal differences were clear from the pore water depth profiles and inventories of key biogeochemical markers, which were calculated for the top $(0-8 \mathrm{~cm})$ and bottom $(12-$ $20 \mathrm{~cm}$ ) sediments (Fig. 2 and Supplementary Materials). In the summer top sediments, the inventories of DOC, $\mathrm{H}_{2} \mathrm{~S}$ and $\mathrm{Fe}^{2+}$ were $11,0.10$, and $0.34 \mu \mathrm{mol} \mathrm{cm}{ }^{-2}$, respectively, or three to five times lower than the corresponding values for winter (Electronic Supplementary Material, Table S1). Similarly, the net sulfate reduction during winter, estimated from sulfate depletion in top sediments, was $11 \mu \mathrm{mol} \mathrm{cm} \mathrm{cm}^{-2}$ but below the detection limit during summer. The low summer values were consistent with enhanced oxidation of $\mathrm{H}_{2} \mathrm{~S}$ because the rates of gross sulfate reduction measured in radiotracer experiments were high year round $(\sim 2 \mu \mathrm{mol}$ $\mathrm{cm}^{-2} \mathrm{da}^{-1}$; Samarkin and Joye, unpublished) [59]. In addition, sediment $\mathrm{O}_{2}$ consumption rates determined in core incubations were significantly higher in summer compared to winter (Porubsky and Joye, unpublished). 


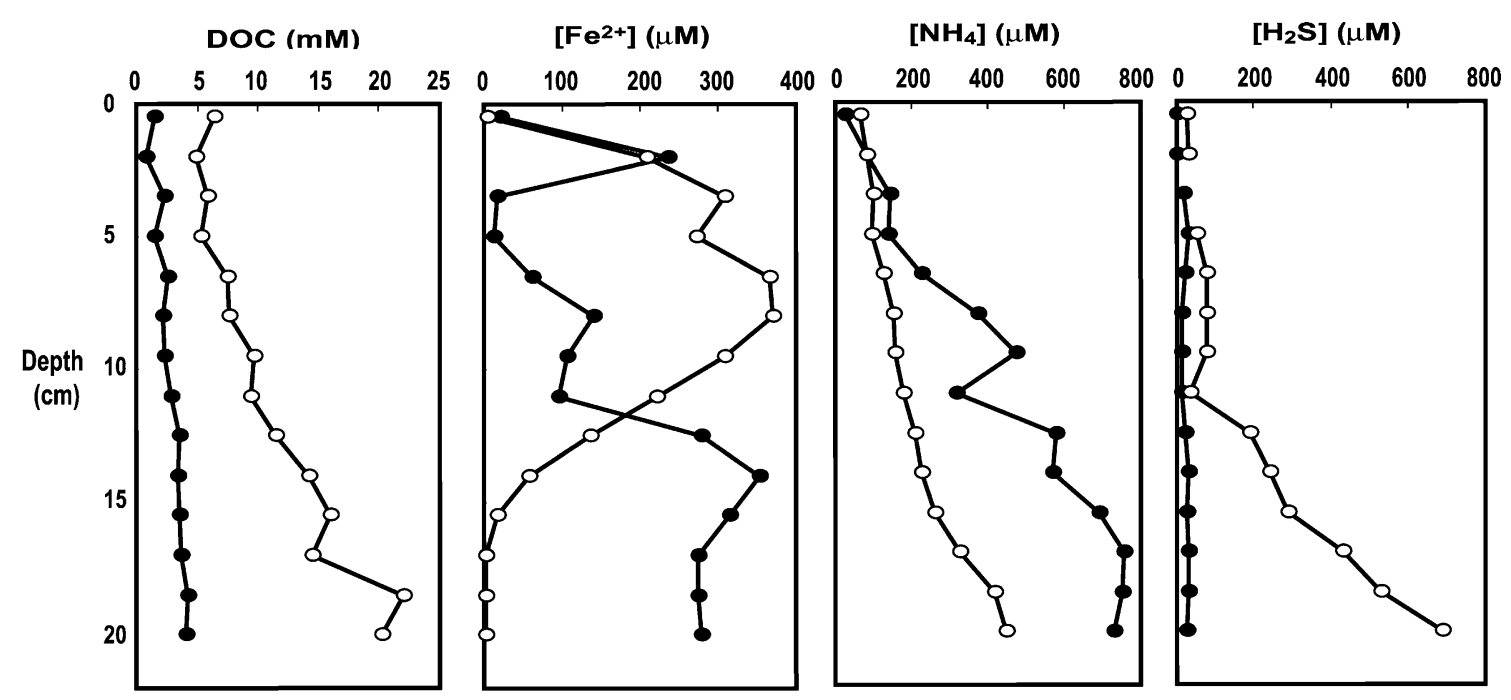

Fig. 2 Composition of the intertidal sediment pore waters in the winter (empty circle) and summer (filled circle) at Dean Creek. The pore water was sampled by diffusion equilibrium samplers or

The enhancement of oxidative processes was attributed to bioturbation by fiddler crabs and other invertebrates [31, 38], which were very active during the summer. These differences are summarized in Fig. 3.

Similar trends were also present in the $12-20 \mathrm{~cm}$ or bottom sediments. Even though the inventories of the "peepers." For winter, data from one sampler is presented. For summer, the data is an average from two samplers

reduced carbon and sulfur compounds increased with depth in both seasons, they remained lower in the summer than in the winter. Similarly, the net sulfate reduction values were 38 and $20 \mu \mathrm{mol} \mathrm{cm} \mathrm{cm}^{-2}$ in the winter and summer, respectively (Electronic Supplementary Material, Table $\mathrm{S} 1)$. Lower inventories of DOC and decreases in net sulfate

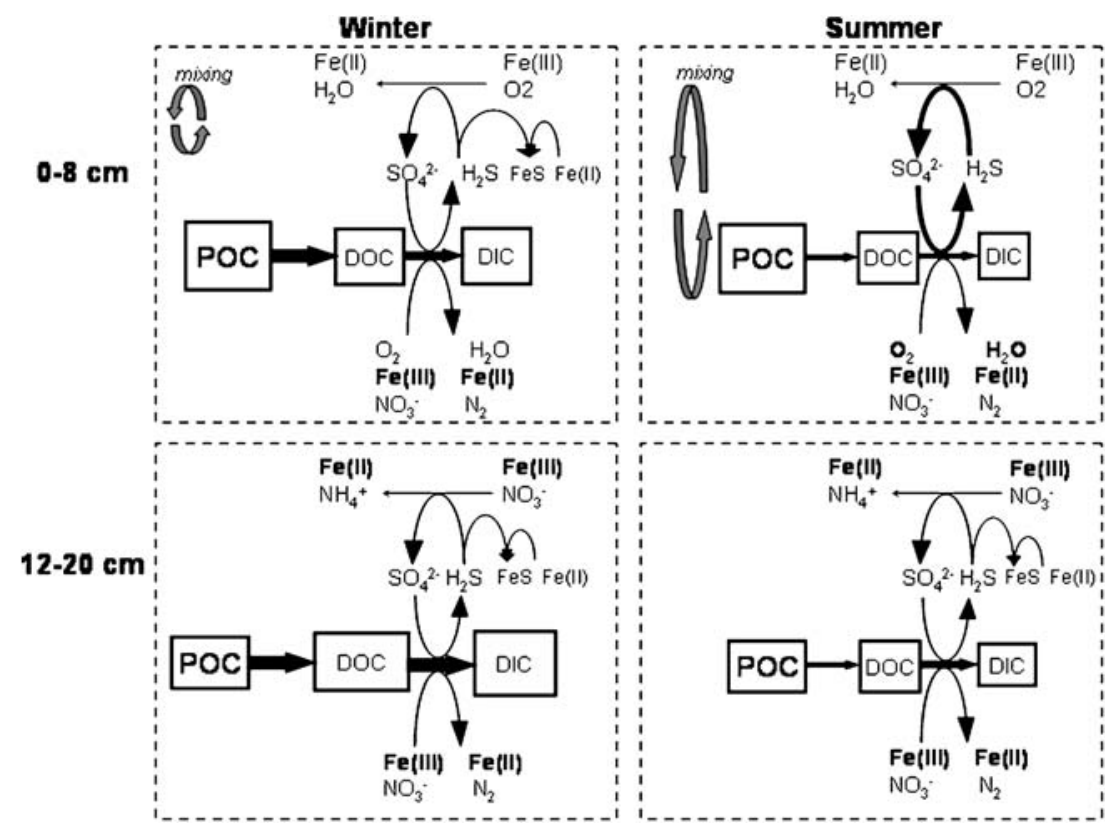

Fig. 3 Models of microbial metabolic processes in Dean Creek sediment during winter and summer at $0-8$ and $12-20 \mathrm{~cm}$ depths. The relative depth of the mixed layer is delineated by the circular arrows. The relative importance of processes is indicated by the thickness of the arrows. In the winter, the limited mixing from bioturbation near the surface lowered the oxidations of DOC and $\mathrm{H}_{2} \mathrm{~S}$, leading to accumulations of DOC, $\mathrm{H}_{2} \mathrm{~S}$, and $\mathrm{FeS}$. In deeper sediments, DOC oxidation was dominated by anaerobic processes. In the summer, extensive mixing by bioturbation at the surface enhanced DOC and $\mathrm{H}_{2} \mathrm{~S}$ oxidation so that these components did not accumulate in spite of higher rates of net sulfate reduction. In deeper sediments, the availability of DOC limited sulfate reduction and other heterotrophic activities. These models were inferred from the composition of the pore waters and the calculated inventories. Abundant substrates are in bold. POC particulate organic carbon, $D O C$ dissolved organic carbon, $D I C$ dissolved inorganic carbon 
reduction, particularly in bottom sediments, suggested that sulfate reduction and other heterotrophic activities were limited by labile DOC availability during summer (Weston and Joye, unpublished). In conclusion, while anaerobic processes dominated sediments in both seasons, oxidation was much more significant in the summer.

While the high levels of sulfide and near absence of methane indicated that sulfate reduction was a major process in these sediments, other respirations also occurred. The magnitude of these processes was estimated from the excess dissolved inorganic carbon (DIC) in the inventory (Electronic Supplementary Material, Table S1). Based upon the stoichiometry of sulfate reduction, the DIC would be twice the net sulfate reduction value if it was the only respiratory process. However, the DIC inventories were 20$60 \mu \mathrm{mol} \mathrm{cm}{ }^{-2}$ greater than expected from sulfate respiration alone (data not shown). Where mixing occurred in the top layer, aerobic respiration was likely to be an important contributor to the total respiration. In the anaerobic zones, microbial iron or manganese reduction, and possibly denitrification, could contribute substantially to organic matter mineralization.

Taxonomic Distribution of $r R N A$ Gene Libraries Libraries of 16S rRNA genes were constructed from environmental DNA extracted from duplicate cores in both the winter and summer. Comparison of the libraries from these duplicates by LIBSHUFF indicated that they were not significantly different, so the libraries from duplicate samples were pooled for most of the subsequent analyses. Genes were assigned to taxonomic groups using RDPquery, a Java application we developed which is described in detail in the Experimental Procedures. This procedure only assigned clones to taxonomic groups when there was a high level of confidence. These assignments were subsequently confirmed by the phylogenetic analyses presented below and in the Supplementary Materials (Figs. S2-S14).

By these criteria, greater than $60 \%$ of the SIMO clones in the sediment libraries were assigned to the Proteobacteria, with the $\gamma$ - and $\delta$-classes predominating (Table 1). Clones from the Bacteroidetes and Cyanobacteria were also well represented. Although most of the clones possessed sufficient sequence similarity to a type strain to be assigned to a phylum, less than $30 \%$ of the clones possessed sufficient similarity ( $\geq 91 \%$ ) to be assigned to an order (Fig. 4). Only a few clones possessed sufficient similarity $(\geq 95 \%)$ to be assigned a genus, indicating that sediment bacteria were poorly represented in culture collections.

On average, clones possessed much higher sequence similarity to other environmental clones than to cultured organisms in the RDP. Even though clones from marine sediments represented a relatively small portion of the RDP database [26], the sequences most similar to the SIMO sequences were also from marine sediments (data not shown). This result suggested that the microbial communities of marine sediments were distinct from those found in sea water, freshwater sediments, soil, and other habitats. In addition, many SIMO clones had only low similarity to clones already in the database. Nearly $25 \%$ of the clones possessed less than $90 \%$ sequence similarity to a previously reported sequence, including clones from environmental DNA (Fig. 4). Thus, bacteria from these sediments are also very poorly sampled even by culture-independent methods.

Community Diversity Based upon the clone libraries, the diversity of the bacterial communities in these sediments was extraordinarily high. When defining the operational taxonomic units or OTUs at $\geq 99 \%$ sequence similarity, the Shannon indices for the individual libraries were all close to the maximum values (Table 2). Even for the library pooled across season and depth of 1,186 clones, the Shannon index remained at $91 \%$ of the maximum value $\left(H / H_{\max }\right.$, Table 2$)$, and the coverage and Chaol estimator were 0.441 and 3,290 , respectively (Table 2 ). When OTUs were defined at $\geq 97 \%$ sequence similarity, the Shannon index remained at $82 \%$ of its maximum value, and coverage and Chao 1 estimator were 0.600 and 2,290, respectively (data not shown). In addition, the diversity appeared higher in the winter than the summer libraries. When matched by depth, the winter libraries always had higher $H / H_{\max }$ values and Chaol estimators than the summer libraries (Table 2). Because of the small number of comparisons (five), this correlation had a $p$ value of only 0.06 by the Sign test [51]. However, for most comparisons, the 95\% confidence intervals of the Chaol estimators for the two seasons did not overlap and the winter values were always higher, further supporting the significance of the difference. A similar increase in diversity in coastal sediments during the winter has been observed by Sorci et al. [54].

When defined at $99 \%$ similarity (or an evolutionary distance of $\leq 0.01$ ), 817 OTUs were identified in the pooled libraries. Because the rarefaction curve failed to plateau (Fig. 5), this value underestimated the total number of OTUs present. When the OTUs were defined more broadly at an evolutionary distance of 0.10 , nearly 200 OTUs were identified, but the rarefaction curve still failed to plateau. Thus, even this fairly large effort failed to fully sample all the deep phylogenetic groups of this community.

Based upon the Shannon indices and Chaol estimators, the bacterial diversity was comparable to that observed in soil by nearly identical methods and greatly exceeded that of estuarine waters (24 and unpublished data). However, because these indices are sensitive to the sample size $[25$, 26], rarefaction curves were also calculated for individual libraries to make a more accurate comparison (Fig. 6). The number of observed OTUs at sample sizes of 50, which 


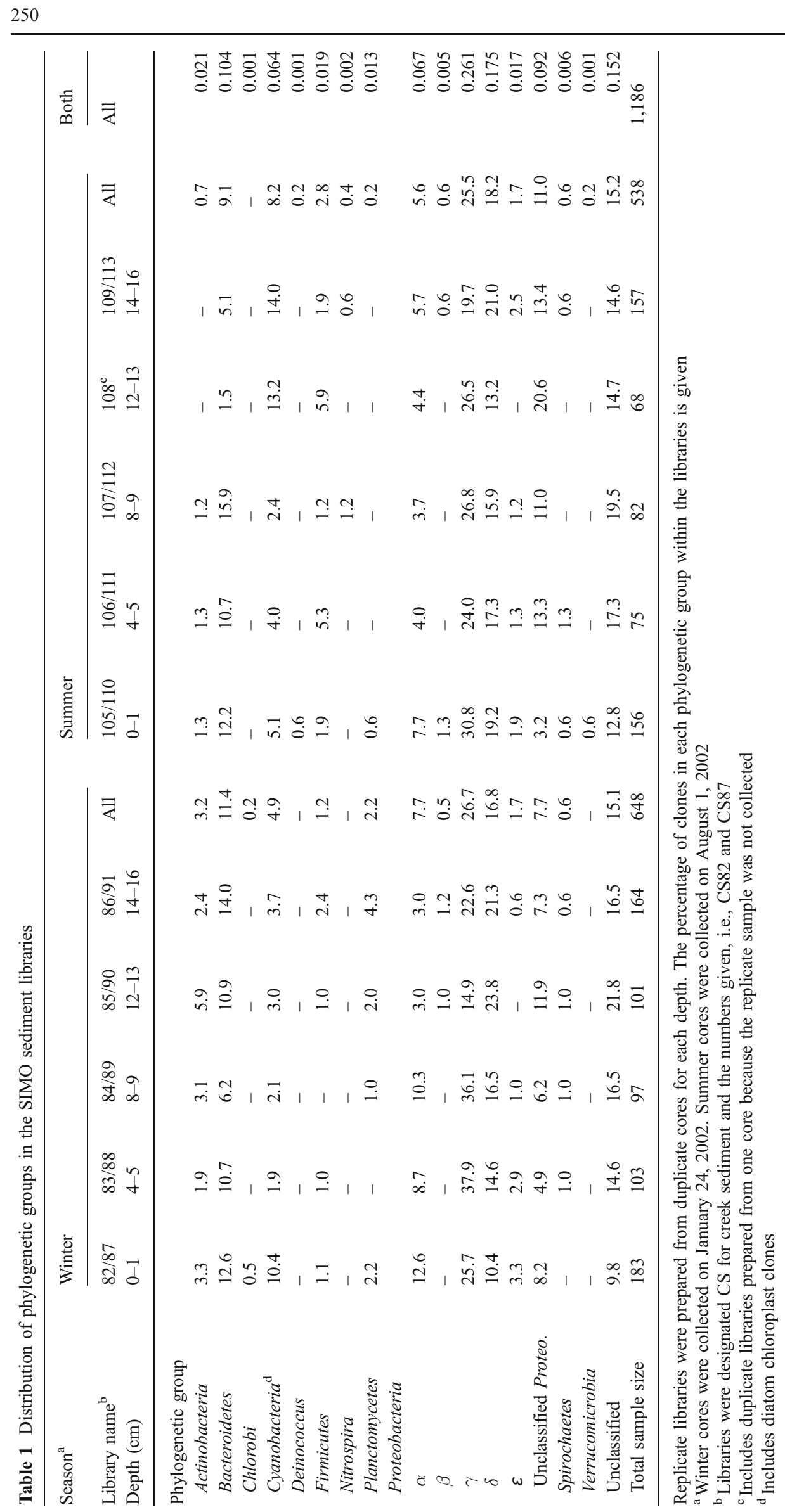

C. Lasher et al.

悬 Springer 

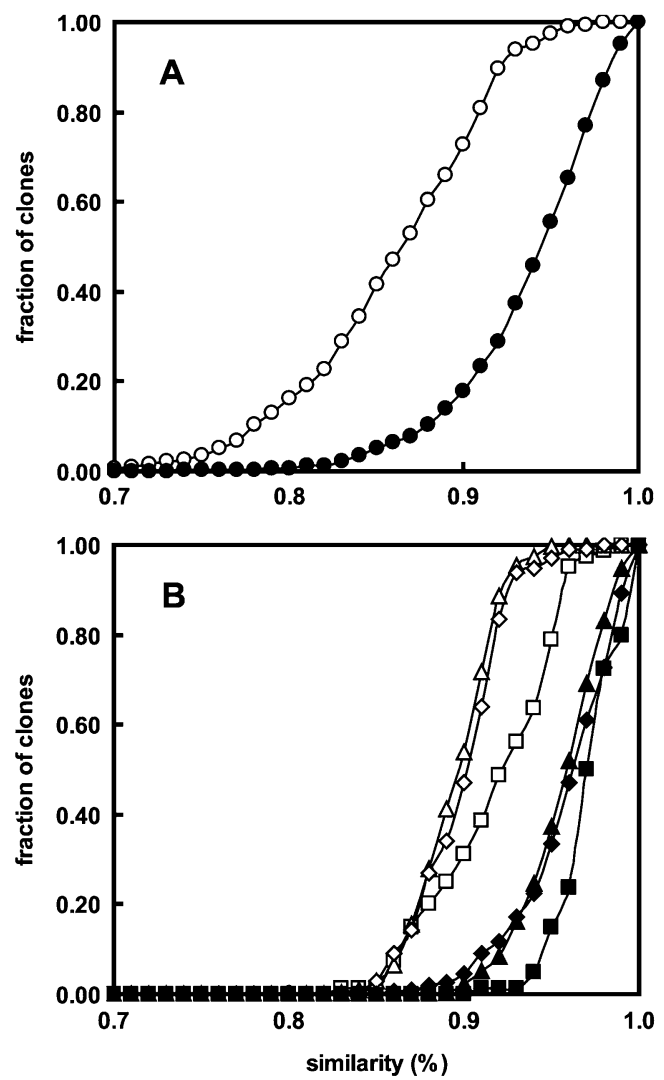

Fig. 4 Similarity of the clone sequences to sequences in the RDP database [version 9.0]. A The fraction of clones within all of the sediment libraries with less than the indicated rRNA sequence similarity to any deposited sequence, which includes the environmental clones plus cultured organisms (filled circle) or to the type strains alone (empty circle). Similarity is defined as the fraction of identical positions divided by the number of positions compared. B The fraction of clones within the $\alpha$-Proteobacteria (filled square, empty square), $\gamma$-Proteobacteria (filled triangle, empty triangle), or $\delta$ Proteobacteria (filled diamond, empty diamond) with less than the indicated rRNA sequence similarity to any deposited sequence (closed symbols) or to the type strains alone (open symbols)

included the smallest library of 68 sequences, were then compared. For sediment and soil, the mean values were very similar, 46.2 $\pm 1.4(n=10)$ and $47.5 \pm 1.5 \quad(n=42)$, respectively (Fig. 6). In contrast, the mean of libraries of estuarine water was only $28.4 \pm 7.2(n=15)$ or much lower. These analyses confirmed that the bacterial communities of these sediments are as diverse as those in agricultural and forest soils [24].

Specific Phylogenetic Groups At $26 \%$ of the total, the $\gamma$ Proteobacteria represented the most abundant taxon in the sediment libraries. Moreover, this group was extraordinarily diverse. At an OTU definition of 99\% similarity, the 311 clones formed 177 OTUs. Rarefaction curves of the OTUs did not approach a plateau, suggesting that this taxon remained greatly under sampled (Fig. 5). Moreover, visual examination of the neighbor-joining tree identified 24 clades of more than two clones with $\mathrm{d}$ values $<0.05$ (or similarity values $>95 \%$; Supplementary Materials). This cutoff was chosen to represent the genus-level groups within this class. In total, these clades contained 285 of the total $311 \gamma$-Proteobacteria clones. The delineation of these smaller groups made it possible to analyze the distribution of groups by season and depth (see below).

Surprisingly for a taxon so well represented in culture collections, the phylogenies of only a few clones were associated with established orders. For instance, $90 \%$ of the clones possessed $<92 \%$ sequence similarity to genes from described organisms (Fig. 4). Similarly, upon phylogenetic analyses, these clones failed to cluster within any of the previously described orders (Fig. 7). Instead, they represented one or more deep phylogenetic groups, with many sequences similar to four clades observed in Antarctic and Tasmania coastal sediments [3]. Even then, most of the SIMO $\gamma$-proteobacterial sequences possessed $<96 \%$ sequence similarity to previously described environmental clones, which illustrated the enormous diversity of this group.

The $\delta$-Proteobacteria represented the second most abundant taxon in the sediment libraries. At $99 \%$ similarity, the 211 clones formed 108 OTUs, which were about onequarter of the 410 estimated to be present by the Chaol. In addition, 19 genus-level clades, representing 189 clones, were also identified as described above for the $\gamma$-Proteobacteria. Although extremely diverse, this group was less diverse than the $\gamma$-Proteobacteria in the same sediments based upon the rarefaction curve (Fig. 4). While most of the clones grouped within the sulfate-reducing bacteria, none of them were closely related to describe taxa. Instead, most were loosely associated with Desulfobulbus (Fig. 8). While Desulfobulbus is common in coastal marine sediments, the absence of many clones related to Desulfosarcina and Desulfococcus distinguished these libraries from those generated of $\delta$-Proteobacteria from salt marshes at Plum Island [28]. In support of this conclusion, nearly half of the SIMO clones possessed $<96 \%$ similarity to other environmental clones in the databases (Fig. 4).

The Proteobacteria were further represented by the $\alpha$ class and large numbers of clones that could not be assigned to any class, designated as the unclassified Proteobacteria. Although these groups only represented $7 \%$ and $9 \%$, respectively, of the libraries, their rarefaction curves overlapped the $\gamma$-proteobacterial curve, suggesting that their diversity was comparable (Fig. 5). At an OTU definition of $99 \%$ similarity, the $80 \alpha$-proteobacterial clones formed 64 OTUs. Eight genus-level clades representing 59 clones were also identified. Although the similarity of the unclassified proteobacterial clones to previously described organisms was too low to assign 


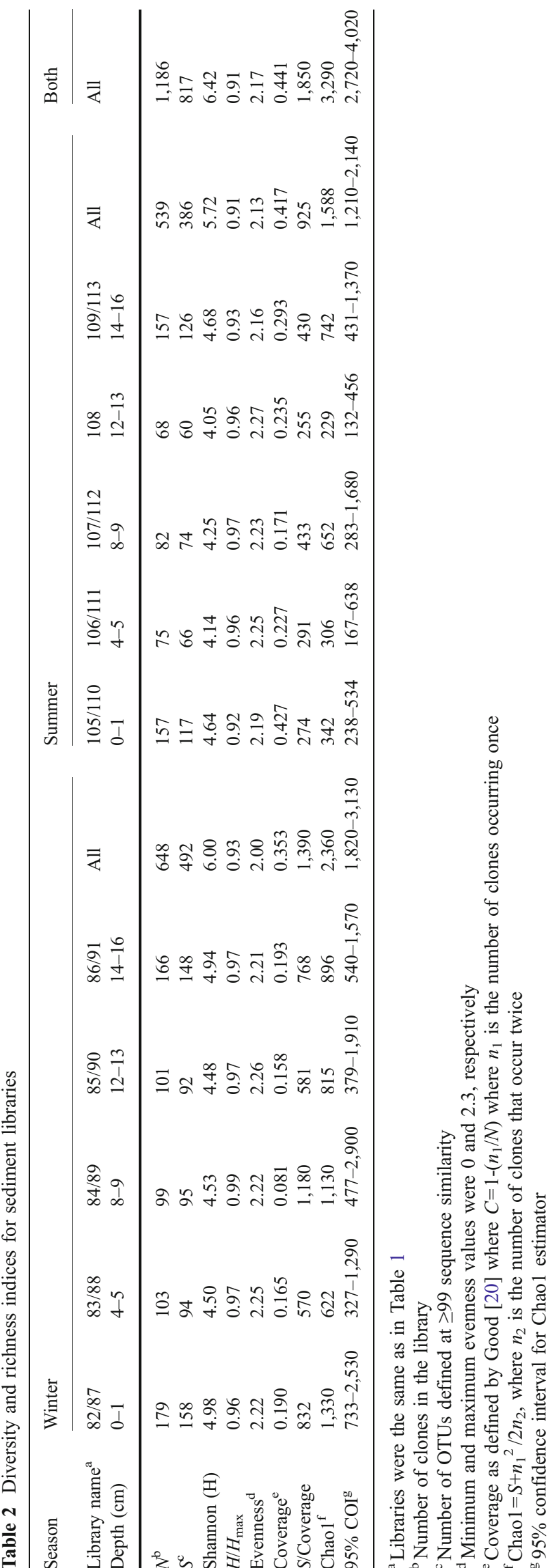

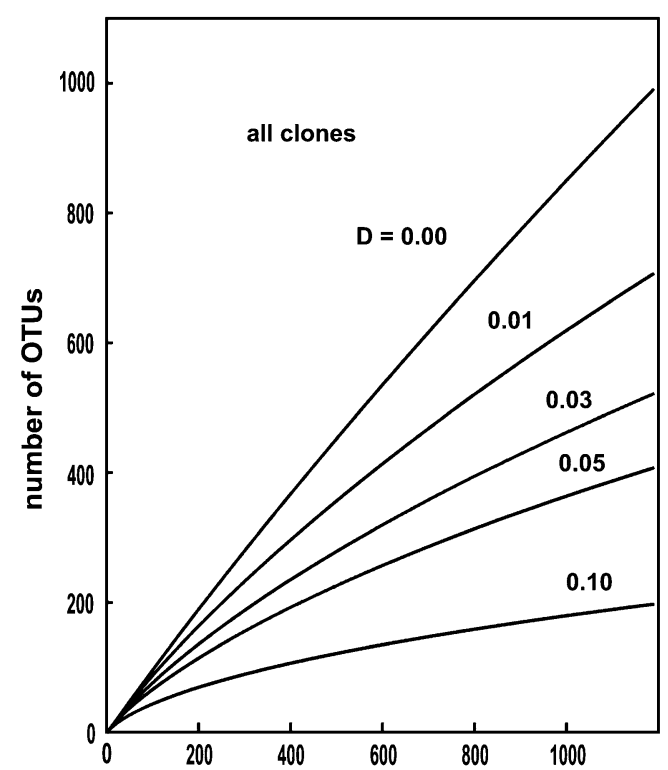

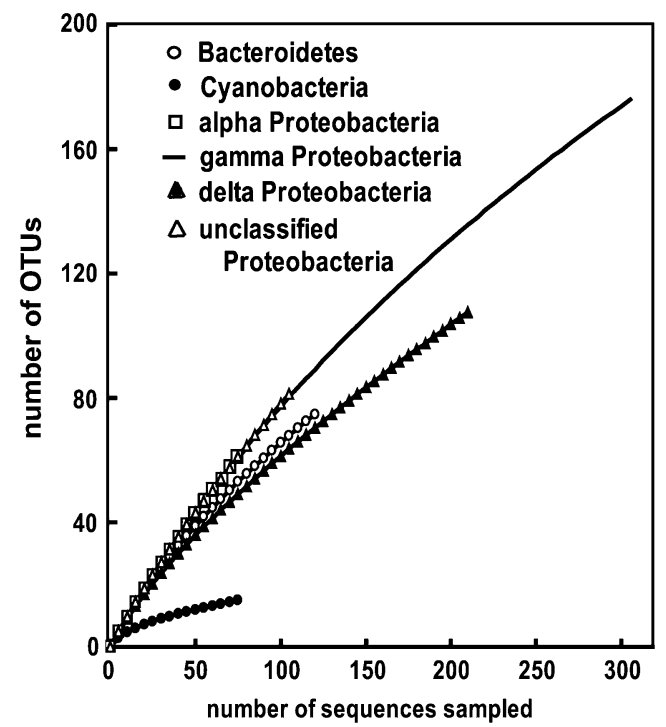

Fig. 5 Rarefaction of clone libraries. (Upper) Analysis of the clones from all libraries with OTUs defined at different evolutionary distances $(D)$. (Lower) Analysis of individual taxa with OTUs defined at $99 \%$ sequence similarity (or $D \sim 0.01$ )

them to an established class, most of these clones were members of one of 13 genus-level clades within four deep phylogenetic groups (Supplementary Materials). Thus, this classification was essentially an artificial assemblage of a small number of unrelated phylogenetic groups with no cultured representatives.

The Bacteroidetes was the third most abundant group. At $99 \%$ similarity, the 123 clones formed 76 OTUs, or about one-third of the 206 Bacteroidetes OTUs estimated to be present by the Chao1. About 13 genus-level clades, representing 96 clones, were also identified. Although many of the clones were related to the Flavobacteriales and Sphingobacterales, nearly half of the clones were not 


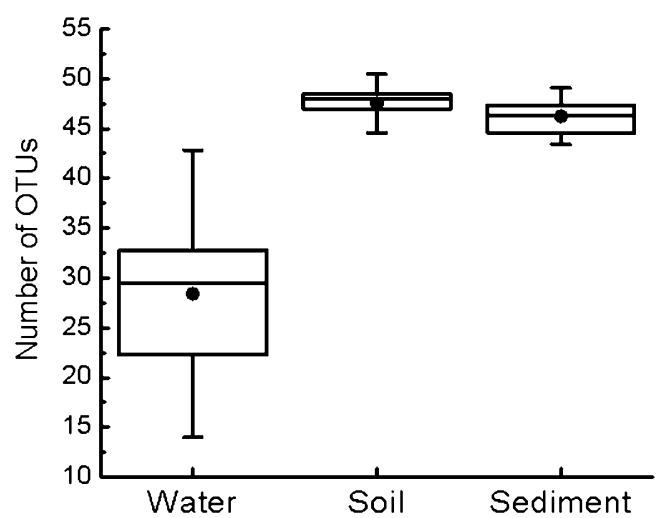

Fig. 6 Comparison of the diversity rRNA gene libraries of soil and estuarine sediment and waters. Libraries were all constructed by low cycle PCR as described in the materials and methods, and rarefaction curves were calculated in DOTUR [49]. Descriptive statistics were then calculated for number of OTUs observed at a sample size of 50 . The box includes the middle two quartiles, the line is the median, filled circle is the mean, bars denote two standard deviations about the mean. The numbers of libraries analyzed were: estuarine waters, 15 (unpublished data); agricultural and forest soils [24], 42; salt marsh sediment, ten (this work)

closely associated with any of the described orders (Supplementary Materials).

Clones from diatom chloroplast and Cyanobacteria represented nearly $7 \%$ of the library. The cyanobacterial clones, of which there were only six, were all from the upper layers of the winter libraries. In contrast, the chloroplast clones were represented by at least five large clades (Supplementary Materials). Compared to the prokaryotic groups, these chloroplast clones were also much less diverse. At $99 \%$ similarity, the 76 clones formed only 15 OTUs, or about one quarter of the 55 OTUs estimated to be present by the Chao1. The rarefaction curve was also much less steep than that of other groups (Fig. 5).

In addition to these major taxa, small numbers of clones were found for a few other groups (Table 1). Although the Actinobacteria represented only $2 \%$ of the clones, they were four times more abundant in the winter (Supplementary Materials). In contrast, 4-6\% of the prokaryotic cells in Waddell Sea sediments hybridized to an actinobacterial probe [55]. Similarly, of the 15 Planctomycetes clones, only one was found in the summer (Supplementary Materials). In contrast, members of the Firmicutes, which were slightly less than $2 \%$ of the clones, were more than twice as abundant in the summer as the winter (Supplementary Materials).

Unclassified Clones About 15\% of the clones could not be assigned to phyla. These 181 clones included 20 genuslevel clades, representing 138 clones. The nearly complete sequences of representative clones of these unclassified groups were obtained to examine their phylogenetic assignments more fully (Fig. 9). These analyses indicated that many of these clones were deep branches of known phyla, but they were only distantly related to described organisms within those phyla.

Variation with Depth and Season Because of the large differences in pore water chemistry with season and depth, differences in the bacterial communities were also expected. This hypothesis was first tested by two-dimensional multidimensional scaling of Bray-Curtis similarity matrices generated from OTUs at $d=0.05$ (Fig. 10). While seasonal differences were found between the libraries, differences with depth were only observed for the winter. Moreover, with the exception of the winter libraries from the bottom depths, the libraries constructed from the duplicate cores in each season were also very similar. Further analyses were then performed to elucidate the nature of the seasonal differences.

Seasonal differences between the libraries could be attributed, at least in part, to differences in the composition or abundance of specific phylogenetic groups. LIBSHUFF is sensitive to differences in composition. When the libraries from all depths for each season were pooled, LIBSHUFF analysis indicated that the libraries were significantly different (Table 3 ). In addition, with the exception of the libraries from the middle depth $(8-9 \mathrm{~cm})$, comparisons between libraries from different seasons but the same depth were also significantly different (data not shown). Further seasonal differences were individually detected for many of the abundant phyla (Table 3). Significant differences were found for the Cyanobacteria and $\alpha-, \gamma$ - and $\delta$-classes of the Proteobacteria. In contrast, the composition of the Bacteroidetes and the unclassified clones did not appear to differ. These conclusions were largely confirmed by ANOSIM analyses in which duplicate libraries were not pooled (Table 3). Therefore, this method accounted for differences in sample variation. By this method, significant seasonal differences were detected for all the groups except the Cyanobacteria. However, the relatively low $R$ values, $0.48-0.81$, suggested that season was only a modest predictor of the bacterial community composition.

In contrast to the season comparisons, LIBSHUFF analyses detected few differences with depth. In the summer, only the libraries from the $0-1 \mathrm{~cm}$ depth were significantly different (data not shown). In the winter, significant differences with depth were not detected. Similarly, while ANOSIM analyses suggested that there were significant differences with depth within the entire data set $(R=0.58, p=0.001)$, it failed to identify differences between specific depths or within specific phylogenetic groups. Lastly, while Chi-squared analyses of the abundance of phylogenetic groups (Table 1) detected some significant differences with depth, the specific nature of 
Fig. 7 Phylogeny of representative $\gamma$-proteobacterial clones. Sequences of the clones are designated " $C S$ " for Creek Sediment followed by a number, a letter, and a second number. The first number represents the library (as defined in Table 1). The letter and second number provide the unique identification of the clone within the library. Representatives of each of the described orders in this class are shown. The phylogenetic tree was constructed by the FITCH method in PHYLIP based upon 585 aligned positions. Bootstrap values were based upon 100 replicates, and only values greater than $50 \%$ are shown. A Neighbor-joining tree for all $\gamma$ proteobacterial clones related to CS83_G05 (see Supplementary Materials). B Phylogeny of the clones related to CS110_H07. Clone libraries CS82-91 and CS105-113 were from the winter and summer, respectively. The scale bars represent JukesCantor evolutionary distances

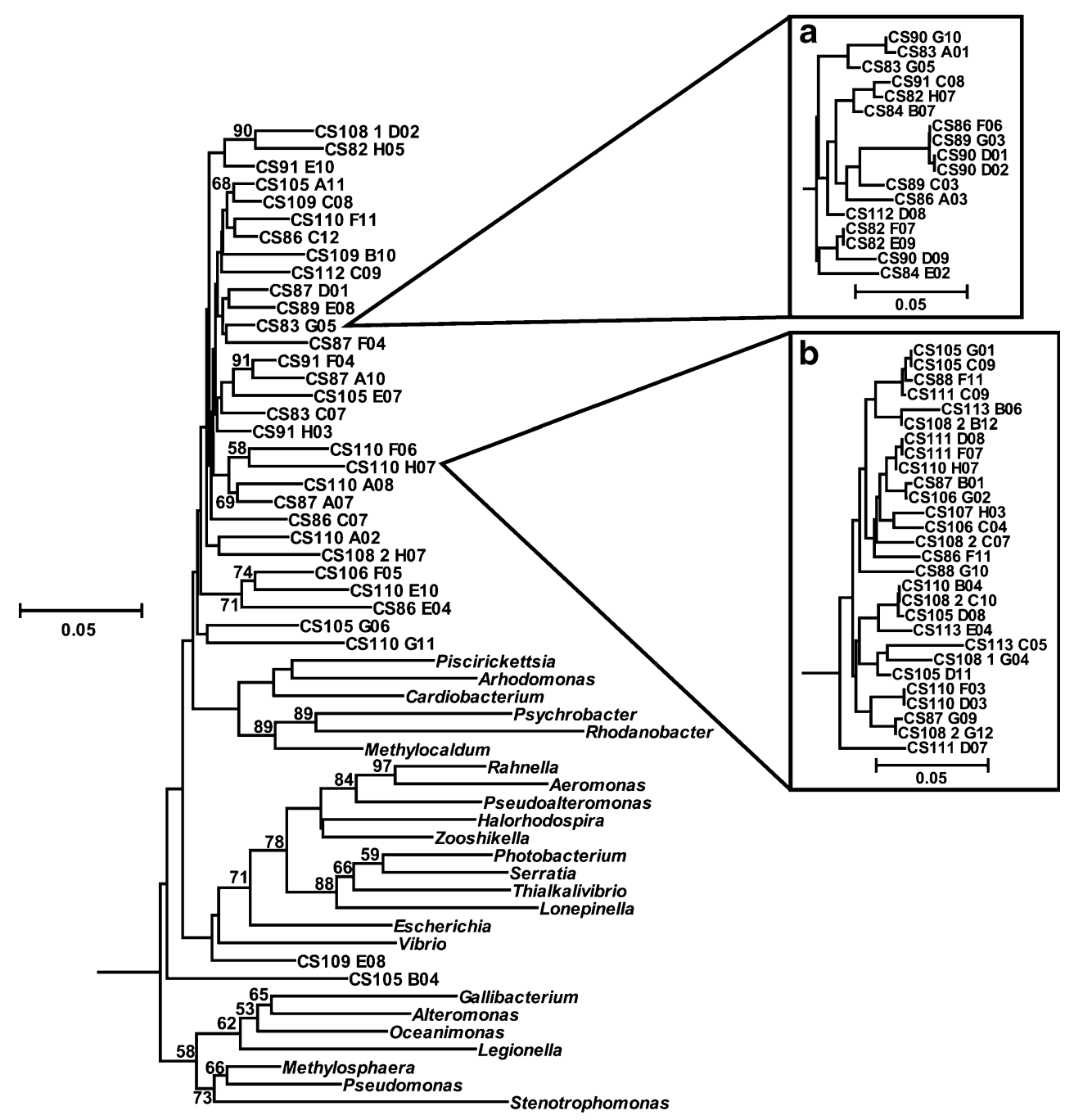

these variations depended upon the season. In the winter libraries, the numbers of cyanobacterial and $\alpha$ - and $\gamma$-proteobacterial clones varied significantly with depth (Chi-squared analysis, $p \leq 0.01$ ). The distribution of the cyanobacteria also varied with depth in the summer, but in the opposite direction. Similarly, in the winter but not the summer, the $\alpha$ - and $\gamma$-proteobacteria varied significantly with depth. Instead, the abundance of the unclassified proteobacteria varied significantly in the summer $(p \leq 0.01)$, being low at the top and highest at the middle depths. Lastly, in the winter but not in the summer, the abundance of the $\delta$-proteobacteria increased with depth $(p \leq 0.05)$. In summary, the response of the bacterial community to depth was complex, and it appeared to involve only a few phylogenetic groups.

Although the variation of the entire bacterial community with season and depth was modest, significant variation was found for some genus-level clades. The strategy implemented here is illustrated in Fig. 7. For groups containing sufficient numbers of clones (such as the genus-level clades), it was possible to test their distribution by the binomial test. For instance, the clade represented by CS83_G05 was significantly more abundant in the winter libraries than the summer $(p<0.05)$. In contrast, the clade represented by CS110_H07 was more abundant in the summer. Of the 24 genus-level clades found in the $\gamma$-Proteobacteria, three clades representing $22 \%$ of the total number of clones varied significantly with season. Twelve clades representing $45 \%$ of the clones were about the same in both seasons. For the remaining nine clades representing $25 \%$ of the clones, the distribution appeared to vary, but this difference was not significant. Similar observations were made with depth. The distribution of two clades representing $8.4 \%$ of the clones varied significantly with depth. The distribution of 13 clades representing $57 \%$ of the clones appeared independent of depth, and distribution of the remainder was uncertain. Similar 
Fig. 8 Phylogeny of representative $\delta$-proteobacterial clones. The phylogenetic tree was constructed by the FITCH method in PHYLIP based upon 320 aligned positions, but otherwise as described for Fig. 7

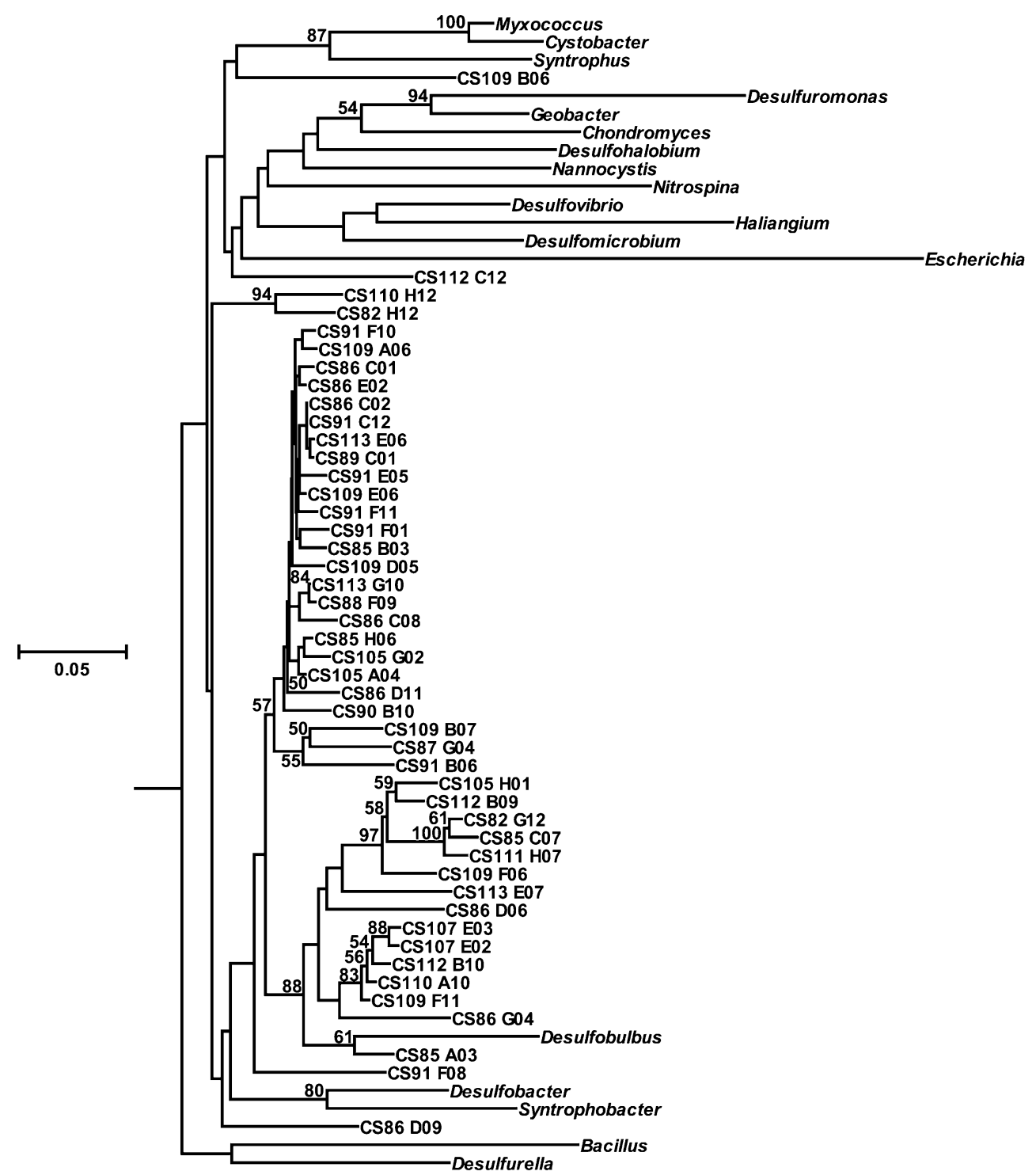

trends were observed among the other phylogenetic groups (data not shown). All together, the distribution of 15 clades from all phyla, representing $19 \%$ of the total number of clones, varied significantly with either season or depth (Table 4). None of these clades contained previously cultured organisms, and the differences in distribution provided circumstantial evidence that their functional roles were distinct.

Although modest, these variations suggested that the distribution of some of the phylogenetic groups may have been responding to specific geochemical properties of the sediments. In fact, the distributions of most groups correlated strongly with $\mathrm{pH}$ and DOC concentration (Table 5). However, $\mathrm{pH}$ and DOC, and to a lesser extend $\mathrm{NH}_{4}^{+}$concentration and salinity, were strongly correlated to season. Therefore, it is not clear whether these groups were responding directly to the geochemical parameters or to another seasonal characteristic, such as temperature. In contrast, the concentrations of $\mathrm{Fe}^{2+}, \mathrm{SO}_{4}^{2-}, \mathrm{NO}_{x}, \mathrm{H}_{2} \mathrm{~S}$, and total dissolved phosphate were not associated with seasonal shifts, and the correlation of these geochemical parameters with specific bacterial groups may be of greater physiological consequence.

\section{Discussion}

The diversity of the bacterial community in these estuarine sediments is very large and comparable to that found in soil. A high level of diversity has been observed previously in libraries from other shallow marine sediments [27, 36, 45] and appears to be common to marine sediments in general [25]. However, the diversity of the SIMO libraries far exceeds previous estimates for shallow marine sediments. For instance, the Chaol estimator for a bacterial library from French Guiana sediments was 226 OTUs [25]. At SIMO, about 800 OTUs (at 99\% similarity) were 
Fig. 9 Phylogeny of representative unclassified clones. The phylogenetic tree was constructed by the FITCH method in PHYLIP based upon 980 aligned positions, but otherwise as described for Fig. 7. Representatives of related taxa are included for comparison

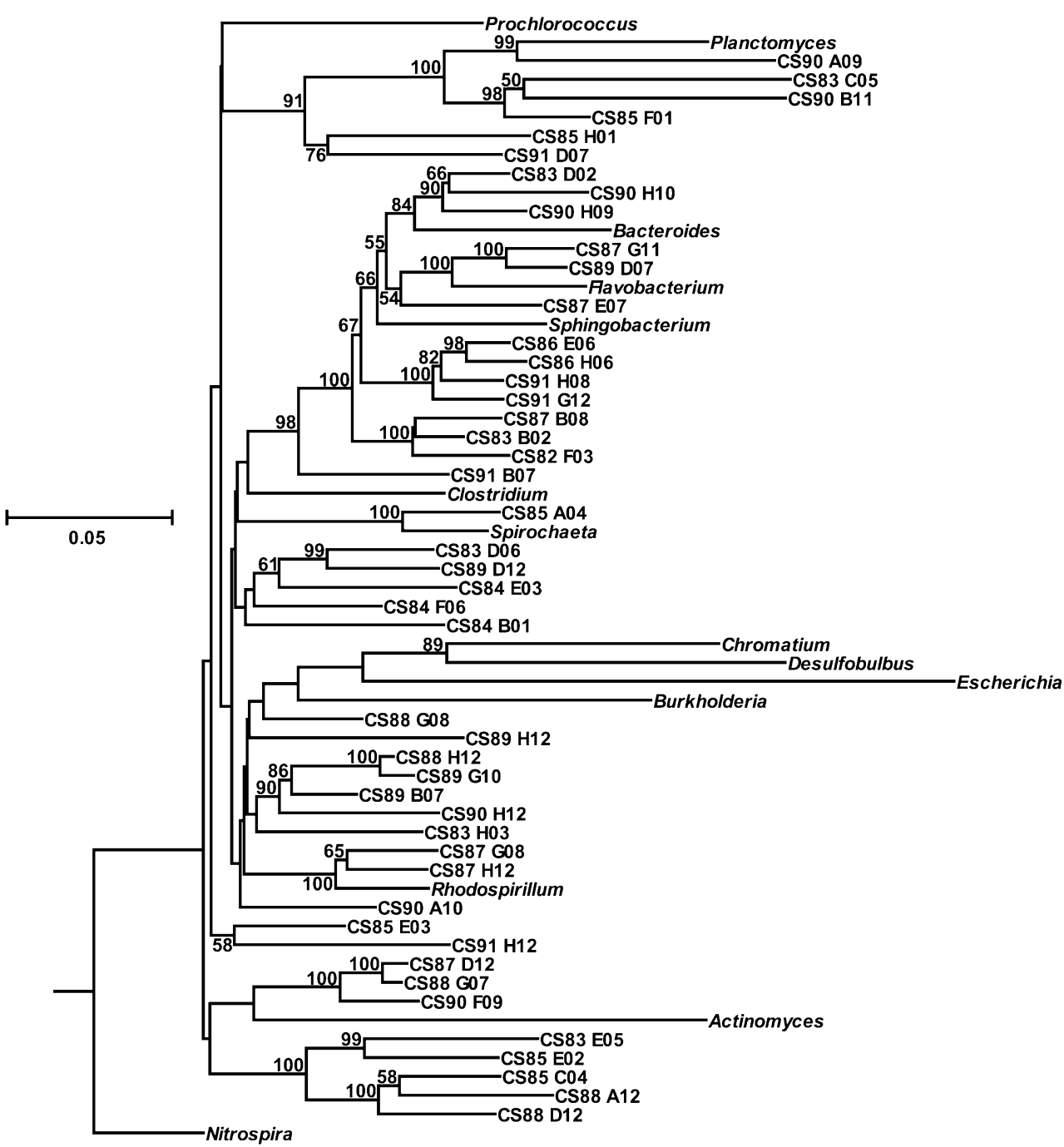

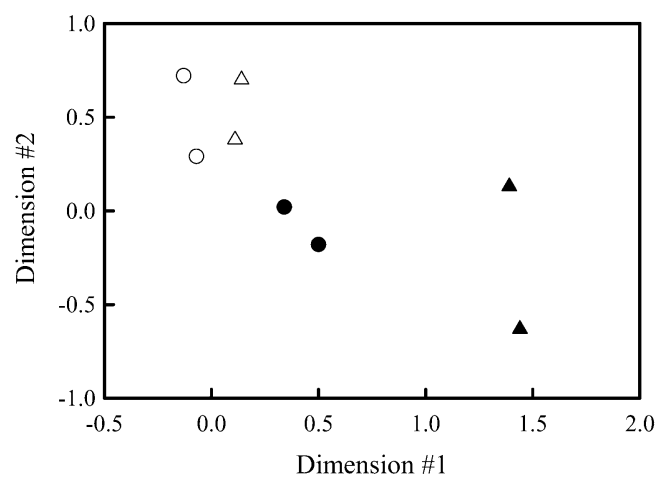

Fig. 10 Variation with season and depth of the Bray-Curtis similarity values of the 16S rRNA gene libraries represented by nonmetric multidimensional scaling. Libraries from the top and bottom of each core were pooled within each season. Winter, $0-5 \mathrm{~cm}$ (filled circle) and $12-16 \mathrm{~cm}$ depths (filled triangle). Summer, $0-5 \mathrm{~cm}$ (empty circle) and $12-16 \mathrm{~cm}$ depths (empty triangle). The closer the points on the graph, the more similar they are in composition actually observed. For $97 \%$ and $99 \%$ similarity, the Chao 1 estimators were 2,290 and 3,290 OTUs, respectively. While methodological differences may account for some of these differences, the much larger sample size of the SIMO libraries certainly plays a role because estimates of diversity generally increase with sample size [26]. Moreover, the high diversity observed at SIMO is consistent with other studies. For instance, within the $\delta$-Proteobacteria, 108 OTUs were observed at SIMO, or about one quarter of the 410 (95\% COI: 258-715) estimated to be present by the Chao1. Comparable richness was observed in a large sampling of just this group in similar anaerobic sediments at Plum Island, where 200 OTUs were observed and 332 OTUs estimated by the Chaol [28]. Importantly, the diversity of the $\delta$-Proteobacteria at SIMO is actually lower than many other taxa in these sediments. Thus, extensive surveys of many taxa will be necessary to fully sample this community.

A number of explanations for the high bacterial diversity of marine sediments are possible. One, the presence of a 
Table 3 LIBSHUFF and ANOSIM comparisons between the Winter and Spring libraries

\begin{tabular}{|c|c|c|c|c|c|}
\hline \multirow[t]{3}{*}{ Comparison } & \multicolumn{3}{|c|}{ LIBSHUFF $^{\mathrm{a}}$} & \multicolumn{2}{|c|}{ ANOSIM $^{\mathrm{b}}$} \\
\hline & \multicolumn{2}{|c|}{ X library } & \multirow{2}{*}{$\frac{\text { Experimentwise }}{P \text { value }}$} & \multirow[t]{2}{*}{$R$} & \multirow[t]{2}{*}{$P$ value } \\
\hline & Winter & Summer & & & \\
\hline All & 0.001 & 0.001 & 0.002 & 0.63 & 0.008 \\
\hline \multicolumn{6}{|c|}{ Phylogenetic group } \\
\hline Bacteroidetes & 0.071 & 0.401 & 0.137 & 0.67 & 0.008 \\
\hline Cyanobacteria & 0.001 & 0.978 & 0.002 & 0.31 & 0.051 \\
\hline \multicolumn{6}{|l|}{ Proteobacteria } \\
\hline$\alpha$ & 0.017 & 0.747 & 0.034 & 0.81 & 0.008 \\
\hline$\gamma$ & 0.001 & 0.003 & 0.002 & 0.57 & 0.008 \\
\hline$\delta$ & 0.004 & 0.001 & 0.002 & 0.48 & 0.008 \\
\hline Unclassified & 0.806 & 0.043 & 0.084 & 0.62 & 0.008 \\
\hline Unclassified & 0.105 & 0.944 & 0.199 & 0.65 & 0.008 \\
\hline
\end{tabular}

${ }^{a} P$ values are reported for $\mathrm{X}$ vs $\mathrm{Y}$ comparisons. The experimentwise $p$ value calculated from the Bonferroni correction

${ }^{\mathrm{b}}$ ANOSIM was performed on Bray-Curtis similarity matrixes for the abundances of OTUs (formed at $d=0.05$ ) with two replicates

solid matrix may allow numerous microhabitats to develop, and different organisms are selected to take advantage of these different habitats. Two, the solid matrix may also limit competition so that colonizers are not rapidly excluded by potentially fitter immigrants or variants. Three, for similar reasons, the complex substrata may make portions of the community inaccessible to predation, which would allow small populations of slowly growing or resting organisms to persist longer. Four, in anaerobic habitats, organisms are more highly specialized for energy sources, such that an entire food chain is necessary to degrade compounds utilized by a single organism under aerobic conditions. Thus, the high diversity may result from both the physical matrix and anaerobic lifestyle.

The overall composition of the SIMO community in terms of the abundances of phyla and other deep taxonomic groups is similar to that found in libraries from other coastal sediments. For instance, $\gamma$ - and $\delta$-Proteobacteria clones are abundant in libraries from SIMO as well as coastal sediments collected worldwide [1, 10, 21, 27, 45, 57]. Exceptions to this pattern have also been observed. The $\alpha$ Proteobacteria dominated shallow sediments collected on

Table 4 Abundant clades whose distribution varied with either season or depth

\begin{tabular}{|c|c|c|c|c|c|c|c|}
\hline \multirow[t]{3}{*}{ Phylogenetic group } & \multirow[t]{3}{*}{ Representative clone } & \multirow[t]{3}{*}{ No. of clones } & \multicolumn{5}{|c|}{ No. of clones within each } \\
\hline & & & \multicolumn{2}{|l|}{ Season } & \multicolumn{3}{|c|}{ Depth $^{a}$} \\
\hline & & & Winter & Summer & Top & Middle & Bottom \\
\hline Actinobacteria & CS90_F09 & 12 & 12 & $\mathbf{0}$ & 6 & 1 & 5 \\
\hline Cyanobacteria & CS109_C11 & 15 & 8 & 7 & 1 & 5 & 9 \\
\hline$\alpha$-Proteobacteria & CS109_H01 & 7 & 1 & 6 & 5 & 0 & 2 \\
\hline \multirow[t]{5}{*}{$\gamma$-Proteobacteria } & CS110_H07 & 28 & 5 & 23 & 18 & 1 & 9 \\
\hline & CS109_B10 & 22 & 20 & 2 & 10 & 1 & 11 \\
\hline & CS83_G05 & 17 & 16 & 1 & 5 & 5 & 7 \\
\hline & CS87_A07 & 15 & 10 & 5 & 11 & 4 & $\mathbf{0}$ \\
\hline & CS110_D02 & 11 & 7 & 4 & 8 & 3 & $\mathbf{0}$ \\
\hline \multirow[t]{4}{*}{$\delta$-Proteobacteria } & CS111_H07 & 23 & 7 & 16 & 15 & 3 & 5 \\
\hline & CS107_E03 & 19 & $\mathbf{0}$ & 19 & 7 & 6 & 6 \\
\hline & CS91_C̄E12 & 13 & 10 & 3 & 1 & 2 & 10 \\
\hline & CS91_B06 & 9 & 8 & 1 & 1 & 1 & 7 \\
\hline Unclassified & CS109_H08 & 15 & 2 & 13 & 7 & 1 & 7 \\
\hline \multirow[t]{2}{*}{ Proteobacteria } & CS105_G10 & 8 & 3 & 5 & 6 & 2 & $\mathbf{0}$ \\
\hline & CS91_G_-G10 & 7 & 6 & 1 & 2 & 1 & 4 \\
\hline
\end{tabular}

Distributions where $p \leq 0.05$ by the binomial test are in bold

${ }^{a}$ Depths correspond to top $(0-5 \mathrm{~cm})$, middle $(8-9 \mathrm{~cm})$, and bottom $(12-16 \mathrm{~cm})$ 
Table 5 Correlation of bacterial phylogenetic groups with pore water geochemistry

\begin{tabular}{llr}
\hline Phylogenetic group & Geochemical variable & Spearman rank correlation $^{\mathrm{a}}$ \\
\hline All & $\mathrm{pH}, \mathrm{DOC}$ & 0.358 \\
Bacteroidetes & $\mathrm{DOC}, \mathrm{TDP}, \mathrm{Fe}^{2+}$ & 0.469 \\
Cyanobacteria & $\mathrm{pH}, \mathrm{SO}_{4}{ }^{2-}$, salinity & 0.252 \\
Proteobacteria & & 0.315 \\
$\alpha$ & $\mathrm{pH}, \mathrm{DOC}, \mathrm{NH}_{4}^{+}, \mathrm{NO}_{x}, \mathrm{Fe}^{2+}$ & 0.238 \\
$\gamma$ & $\mathrm{pH}, \mathrm{DOC}, \mathrm{NH}_{4}^{+}$ & 0.241 \\
$\delta$ & $\mathrm{pH}, \mathrm{DOC}$ & 0.310 \\
Unclassified Proteo. & $\mathrm{pH}, \mathrm{H}_{2} \mathrm{~S}$, salinity & \\
\hline
\end{tabular}

Correlations were calculated with the BVSTEP software between the Bray-Curtis similarity matrixes for the abundances of OTUs (formed at $d=$ 0.05 ) and the geochemical variables $\mathrm{pH}, \mathrm{DOC}$ (dissolved organic carbon), $\mathrm{Fe}^{2+}, \mathrm{TDP}, \mathrm{SO}_{4}^{2-}$, salinity, $\mathrm{NH}_{4}^{+}, \mathrm{NO}_{\mathrm{x}}$, and $\mathrm{H}_{2} \mathrm{~S}$

${ }^{a}$ All correlations were significant with $p$ values of $<0.0005$. Supplemental Data: Lasher et al. "The diverse bacterial community in intertidal, anaerobic sediments at Sapelo Island, Georgia"

TDP total dissolved phosphate

the coast of French Guiana [34], and this group was relatively minor in the SIMO libraries. The Actinobacteria, which were a minor component of the SIMO libraries, were likewise common in French Guiana sediments. Similarly, Bacteroidetes dominated cells detected by FISH in intertidal mud flats of the Wadden Sea [33] and have been cultivated from salt marshes in the Virginia Coastal Reserve [35], but were only the third most abundant taxon in the SIMO libraries. Lastly, Firmicutes dominated libraries from anoxic sediments from saline meromictic lakes and a coastal marine basin in Antarctica [4] but were of low abundance in the SIMO libraries. These results suggest that the proportions of the deep phylogenetic groups in the microbial communities at SIMO are typical but not universal of that found in coastal sediments.

Because of the high diversity and low sampling coverage of sediment communities, it is difficult to ascertain if these similarities in overall composition at the phylum level extend to the species and genus levels. However, because the populations of the sulfate-reducing bacteria have been examined in detail in both libraries and hybridization experiments, it is possible to make more detailed comparisons for this group. In the SIMO libraries, clones related to Desulfobulbus represent nearly $18 \%$ of the total clones and most of the $\delta$-Proteobacteria. Hybridization of probes to environmental DNA found the total amount of sulfatereducing bacteria in creek bank sediments at the adjacent Institute Marsh at Sapelo Island to be similar [30], and the sulfate-reducing bacteria have been estimated to be $5-25 \%$ of the bacterial rRNA in other coastal sediments [16, 39, $40,43,47,48]$. Thus, the overall abundance of this group at Sapelo Island is typical of that found in a wide variety of coastal marine sediments.

Although the sizes of the $\delta$-proteobacterial communities are similar in marine sediments from different sites, the members are very different. Based upon their sequences, $<5 \%$ of the SIMO clones would be expected to hybridize to the probes which hybridized strongly to nucleic acids from other coastal sediments. These include probe 129 for Desulfobacter, probe A01-183 for Desulfonema, probe 687 for Desulfovibrio and Desulfomonas, and probes 804 and 814 for Desulfosarcina, Desulfococcus, and related taxa. In support of this conclusion, only a small fraction (0$5 \%$ ) of the prokaryotic rRNA extracted from the upper $20 \mathrm{~cm}$ of creek bank sediments from Institute Marsh hybridized to probes 687 and 804 [30]. Instead, most of the SIMO $\delta$-proteobacterial clones would be expected to hybridize to probe DSR651, which hybridized to only 1$2 \%$ of the bacterial cells in sediments from the Wadden Sea [39]. Finally, there is only low sequence similarity of the SIMO clones to other environmental clones, including those from a large library of $\delta$-Proteobacteria clones from Spartina marsh sediments at Plum Island, MA, USA [28]. These results suggest that the populations of sulfate-reducing bacteria in the SIMO community are quite distinct from those found in other marine sediments. Three explanations are likely for the differences observed between these communities of sulfate-reducing bacteria. One, the physiology of these bacteria is diverse and includes the abilities to use a variety of electron donors and acceptors as well as disproportionate sulfur compounds [44]. Their distribution may reflect different physiological capabilities of these phylogenetic groups. However, in the absence of cultured representatives from the Sapelo Island sediments, it is difficult to predict what these traits might be. Two, at any particular location, the distribution of sulfate-reducing bacteria as well as other bacteria depends greatly upon specific landscape features, including the presence and type of vegetation as well as season $[5,6,30,34,46,53]$. Thus, the SIMO community appears unique because other sites with precisely matched landscape features have not yet been studied. Three, communities of sulfate-reducing bacteria may vary depending upon the climate or other global factors. For instance, a strong biogeographic effect on the bacterial 
community has been noted by T-RFLP analyses of sediment communities from the east coast of the US [2]. Presumably, these differences are responses to changes in temperature, vegetation, precipitation, and seasonal patterns. An important implication of these results is that intensive sampling of the diversity of sulfate-reducers, and presumably other groups of prokaryotes, at one site is unlikely to capture the full diversity in nature. Thus, the sulfate-reducing bacteria are under sampled not only because no location has been sampled to completion but also because not all types of locations have yet been sampled.

In spite of the steep chemical gradients in the pore waters, only modest differences with depth were observed in the bacterial communities in both the winter and summer cores. This conclusion was consistent with both the LIBSHUFF analyses as well as the detailed analyses of specific clades. Because of their high abundance, the pattern is most clearly illustrated for the $\gamma$ - and $\delta$ Proteobacteria. Of the 43 clades identified in these classes, the abundance of only four, representing about $12 \%$ of the clones, varied significantly with depth. An additional $26 \%$ of the clones belonged to 16 clades whose abundances tended to vary with depth, but these differences were not significant. Presumably, if larger libraries had been constructed, the distributions of some but not all of these clades would have been significantly different. Finally, $53 \%$ of the clones were in 23 clades whose abundance was uniform with depth. The remaining $9 \%$ of the clones could not be assigned to clades. Thus, a picture emerges of populations that contain a large component (53-79\% of the clones) whose relative abundance is unaffected by depth and a small component (12-38\% of the clones) whose abundance is strongly dependent on depth. These general conclusions are consistent with other studies of coastal sediments. Koretsky et al. [30] also failed to observe a strong correlation of microbial community structure with geochemical gradients in Institute Marsh sediments. Using FISH, Llobet-Brossa et al. [33] observed two- to threefold changes in the relative fraction of cells that hybridized to both general and specific probes in the upper $5 \mathrm{~cm}$ of intertidal mud flats in the Wadden Sea. Similarly, based upon quantitative hybridization studies of sulfate-reducing bacteria, changes in abundances with depth in the upper $10-15 \mathrm{~cm}$ depend greatly upon the phylogenetic group [16, $39,48]$.

Somewhat larger seasonal shifts in the populations were observed. These differences were readily detected by LIBSHUFF and upon examination of the 43 genus-level clades of the $\gamma$ - and $\delta$-Proteobacteria. For these groups, the abundance of 6 clades containing $20 \%$ of the clones varied significantly with the season. An additional $38 \%$ of the clones belonged to 21 clades whose abundances tended to vary with season, but these differences were not significant.
Finally, $33 \%$ of the clones were in 16 clades whose abundances were independent of season. Thus, a picture emerges of two populations of comparable size. The abundance of members of one population, $33-71 \%$ of the total, is unaffected by season. The abundances of members of the second population, $20-58 \%$ of the total, depend on season. In constrast, the bacterial communities of many terrestrial soils are unaffected by season [24].

In conclusion, the high diversity of the microbial communities in the SIMO sediments is striking. Even this fairly large sequencing effort failed to fully sample the community, and many fairly broad OTUs, such as those formed at $90 \%$ sequence similarity, remained unsampled. As an additional consequence of this large diversity, most of the SIMO sequences are unique and have not been encountered in previous investigations of estuarine or other sediments. Likewise, most of the SIMO sequences have only low similarity to cultured organisms. Importantly, the high diversity is not restricted to a few taxa. Instead, it is a general property of many of the phylogenetic groups encountered in these sediments. Moreover, while the overall diversity and abundance of many phyla of the SIMO bacterial community is similar to other marine sediments, the composition is different at the genus level for the sulfate-reducing bacteria and presumably other groups as well. This result implies that the enormous diversity of marine sediments extends not only within sediments but also between sediments.

While it has been possible to identify clades of abundant, uncultivated bacteria within the SIMO sediments, it has generally not been possible to infer their physiological properties in the absence of close relatives in culture. Nevertheless, a picture emerged of a complex population composed of both resident taxa that were abundant in both seasons and all depths and transient taxa, whose abundance fluctuated. Nevertheless, the association of members of this rich bacterial community with specific geochemical processes remains a tremendous challenge as well as opportunity for elucidating fundamental microbial processes in these sediments.

Acknowledgments This work was supported in part by the National Science Foundation Microbial Observatories Program and the Gordon and Betty Moore Foundation. The geochemical data presented here were supported by the Georgia Coastal Ecosystems LTER program. We also thank Nat Weston and Bill Porubsky for assisting with sample collection and geochemical analyses and Rima Upchurch for helpful discussions.

Open Access This article is distributed under the terms of the Creative Commons Attribution Noncommercial License which permits any noncommercial use, distribution, and reproduction in any medium, provided the original author(s) and source are credited. 


\section{References}

1. Asami H, Aida M, Watanabe K (2005) Accelerated sulfur cycle in coastal marine sediment beneath areas of intensive shellfish aquaculture. Appl Environ Microbiol 71:2925-2933

2. Blum LK, Roberts MS, Garland JL, Mills AL (2004) Distribution of microbial communities associated with the dominant high marsh plants and sediments of the United States East Coast. Microbial Ecol 48:375-388

3. Bowman JP, McCammon SA, Dann AL (2005) Biogeographic and quantitative analyses of abundant uncultivated $\gamma$-proteobacterial clades from marine sediment. Microbial Ecol 49:451-460

4. Bowman JP, Rea SM, McCammon SA, McMeekin TA (2000) Diversity and community structure within anoxic sediment from marine salinity meromictic lakes and a coastal meromictic marine basin, Vestfold Hills, Eastern Antarctica. Environ Microbiol 2:227-237

5. Burke DJ, Hamerlynck EP, Hahn D (2002) Interactions among plant species and microorganisms in salt marsh sediments. Appl Environ Microbiol 68:1157-1164

6. Burke DJ, Hamerlynck EP, Hahn D (2003) Interactions between the salt marsh grass Spartina patens, arbuscular mycorrhizal fungi and sediment bacteria during the growing season. Soil Biol Biochem 35:501-511

7. Cai WJ, Wang Y (1998) The chemistry, fluxes, and sources of carbon dioxide in the estuarine waters of the Satilla and Altamaha Rivers, Georgia. Limnol Oceanogr 43:657-668

8. Chalmers AG (1997) The ecology of the Sapelo Island National Estuarine Research Reserve. Office of Coastal Resource Management, National Oceanic and Atmospheric Administration, Washington, D.C

9. Chmura GL, Anisfeld SC, Cahoon DR, Lynch JC (2003) Global carbon sequestration in tidal, saline wetland soils. Global Biogeochem Cycles 17:1111. doi:10.1029/2002GB001917

10. Cifuentes A, Antón J, Benlloch S, Donnelly A, Herbert RA, Rodríguez-Valera F (2000) Prokaryotic diversity in Zostera noltiicolonized marine sediments. Appl Environ Microbiol 66:17151719

11. Clarke KR (1993) Non-parametric multivariate analyses of changes in community structure. Aust J Ecol 18:117-143

12. Clarke KR, Green RH (1988) Statistical design and analysis for a "biological effects" study. Mar Ecol Prog Ser 46:213-226

13. Clarke KR, Warwick RM (2001) Change in Marine Communities: An Approach to Statistical Analysis and Interpretation, 2nd edn. Plymouth Marine Laboratory, Plymouth

14. Cole JR, Chai B, Farris RJ, Wang Q, Kulam SA, McGarrell DM, Garrity GM, Tiedje JM (2005) The Ribosomal Database Project (RDP-II): sequences and tools for high-throughput rRNA analysis. Nucleic Acids Res 33:D294-D296. doi:10.1093/nar/gki038

15. DeSantis TZ, Hugenholtz P, Larsen N, Rojas M, Brodie EL, Keller K, Huber T, Dalevi D, Hu P, Anderson GL (2006) Greengenes, a chimera-checked 16S rRNA gene database and workbench compatible with ARB. Appl Environ Microbiol 72:5069-5072

16. Devereux R, Winfrey MR, Winfrey J, Stahl DA (1996) Depth profile of sulfate-reducing bacterial ribosomal RNA and mercury methylation in an estuarine sediment. FEMS Microbiol Ecol 20:23-31

17. Dollhopf SL, Hyun JH, Smith AC, Adams HJ, O'brien S, Kostka JE (2005) Quantification of ammonia-oxidizing bacteria and factors controlling nitrification in salt marsh sediments. Appl Environ Microbiol 71:240-246

18. Everitt B (1980) Cluster analysis, 2nd edn. Heinemann, London

19. Garrity GM, Holt JG (2001) The road map to the Manual. In: Boone DR, Castenholz RW (eds) Bergey's Manual of Systematic Bacteriology, vol. 1. Springer, New York, pp 119-166
20. Good IJ (1953) The population frequencies of species and the estimation of population parameters. Biometrica 40:1107-1114

21. Gray JP, Herwig RP (1996) Phylogenetic analysis of the bacterial communities in marine sediments. Appl Environ Microbiol 62:4049-4059

22. Hesslein RH (1976) An in situ sampler for close interval pore water studies. Limnol Oceanogr 21:912-914

23. Hussein AH, Rabenhorst MC, Tucker ML (2004) Modeling of carbon sequestration in coastal marsh soils. Soil Sci Soc Am J 68:1786-1795

24. Jangid K, Williams MA, Franzluebbers AJ, Sanderlin JS, Reeves JH, Jenkins MB, Endale DM, Coleman DC, Whitman WB (2008) Relative impacts of land-use, management intensity and fertilization upon soil microbial community structure in agricultural systems. Soil Biol Biochem 40:2843-2853

25. Kemp PF, Aller JY (2004) Bacterial diversity in aquatic and other environments: what $16 \mathrm{~S}$ rDNA libraries can tell us. FEMS Microbiol Ecol 47:161-177

26. Kemp PF, Aller JY (2004) Estimating prokaryotic diversity: when are 16S rDNA libraries large enough? Limnol Oceanogr Meth 2:114-125

27. Kim B-S, Oh H-M, Kang H, Park S-S, Chun J (2004) Remarkable bacterial diversity in the tidal flat sediment as revealed by $16 \mathrm{~S}$ rRNA analysis. J Microbiol Biotechnol 14:205-211

28. Klepac-Ceraj V, Bahr M, Crump BC, Teske AP, Hobbie JE, Polz MF (2004) High overall diversity and dominance of microdiverse relationships in salt marsh sulphate-reducing bacteria. Environ Microbiol 6:686-698

29. Koretsky CM, Moore CM, Lowe KL, Meile C, DiChristina TJ, Van Cappellen P (2003) Seasonal oscillation of microbial iron and sulfate reduction in saltmarsh sediments (Sapelo Island, GA, USA). Biogeochemistry 64:179-203

30. Koretsky CM, Van Cappellen P, DiChristina TJ, Kostka JE, Lowe KL, Moore CM, Roychoudhury AN, Viollier E (2005) Salt marsh pore water geochemistry does not correlate with microbial community structure. Estuarine Coastal and Shelf Science 62:233-251

31. Kostka JE, Gribsholt B, Petrie E, Dalton D, Skelton H, Kristensen E (2002) The rates and pathways of carbon oxidation in bioturbated saltmarsh sediments. Limnol Oceanogr 47:230-240

32. Kumar S, Tamura K, Nei M (2004) MEGA3: Integrated Software for Molecular Evolutionary Genetics Analysis and Sequence Alignment. Brief Bioinform 5:150-163

33. Llobet-Brossa E, Rosselló-Mora R, Amann R (1998) Microbial community composition of Wadden Sea sediments as revealed by fluorescence in situ hybridization. Appl Environ Microbiol 64:2691-2696

34. Lowe KL, DiChristina TJ, Roychoudhury AN, Van Cappellen P (2000) Microbiological and geochemical characterization of microbial $\mathrm{Fe}(\mathrm{III})$ reduction in salt marsh sediments. Geomicrobiology J 17:163-178

35. Lydell C, Dowell L, Sikaroodi M, Gillevet P, Emerson D (2004) A population survey of members of the phylum Bacteroidetes isolated from salt marsh sediments along the East Coast of the United States. Microbial Ecol 48:263-273

36. Madrid VM, Aller JY, Aller RC, Chistoserdov AY (2001) High prokaryote diversity and analysis of community structure in mobile mud deposits off French Guiana: identification of two new bacterial candidate divisions. FEMS Microbiol Ecol 37:197-209

37. Magurran AE (1988) Ecological diversity and its measurement. Princeton University Press, Princeton

38. Meile C, Koretsky CM, Van Cappellen P (2001) Quantifying bioirrigation in aquatic sediments: an inverse modeling approach. Limnol Oceanogr 46:164-177

39. Mußmann M, Ishii K, Rabus R, Amann R (2005) Diversity and vertical distribution of cultured and uncultured Deltaproteobacteria in an intertidal mud flat of the Wadden Sea. Environ Microbiol 7:405-418 
40. Nedwell DB, Embley TM, Purdy KJ (2004) Sulphate reduction, methanogenesis and phylogenetics of the sulphate reducing bacterial communities along an estuarine gradient. Aquatic Microbial Ecol 37:209-217

41. Nicholas KB, Nicholas HB Jr, Deerfield DW II (1997) GeneDoc: Analysis and Visualization of Genetic Variation, EMBNEW. NEWS 4:14. http://www.psc.edu/biomed/genedoc.

42. Pomeroy LR, Wiegert RG (1981) Ecology of a salt marsh. Springer, New York

43. Purdy KJ, Nedwell DB, Embley T, Takii S (2001) Use of $16 \mathrm{~S}$ rRNA-targeted oligonucleotide probes to investigate the distributiojn of sulphate-reducing bacteria in estuarine sediments. FEMS Microbiol Ecol 36:165-168

44. Rabus R, Hansen TA, Widdel F (2006) Dissimilatory sulfate- and sulfur-reducing prokaryotes. In: Dworkin M, Falkow S, Rosenberg E, Schleifer K-H, Stackebrandt E (eds) Prokaryotes vol. 2. Springer, New York, pp 659-768

45. Ravenschlag K, Sahm K, Pernthaler J, Amann R (1999) High bacterial diversity in permanently cold marine sediments. Appl Environ Microbiol 66:3592-3602

46. Ravit B, Ehrenfeld JG, Haggblom MM (2003) A comparison of sediment microbial communities associated with Phragmites australis and Spartina alterniflora in two brackish wetlands of New Jersey. Estuaries 26:465-474

47. Rooney-Varga JN, Devereux R, Evans RS, Hines ME (1997) Seasonal changes in the relative abundance of uncultivated sulfate-reducing bacteria in a salt marsh sediment and in the rhizophere of Spartina alterniflora. Appl Environ Microbiol 63:3895-3901

48. Sahm K, MacGregor B, Jorgensen BB, Stahl DA (1999) Sulphate reduction and vertical distribution of sulphate-reducing bacteria quantified by rRNA slot-blot hybridization in a coastal marine sediment. Environ Microbiol 1:65-74

49. Schloss PD, Handelsmann J (2005) Introducing DOTUR, a computer program for defining operational taxonomic units and estimating species richness. Appl Environ Microbiol 71:1501-1506
50. Shannon CE, Weaver W (1963) The mathematical theory of communication. Univ. Illinois Press, Urbana, p 117

51. Siegel S (1956) Nonparametric statistics for the behavioral sciences. McGraw-Hill, New York, pp 36-42

52. Singleton DR, Furlong MA, Rathbun SL, Whitman WB (2001) Quantitative comparisons of 16S rRNA gene sequence libraries from environmental samples. Appl Environ Microbiol 67:43744376

53. Smith AC, Kostka JE, Devereux R, Yates DF (2004) Seasonal composition and activity of sulfate-reducing prokaryotic communities in seagrass bed sediments. Aquatic Microbial Ecol 37:183-195

54. Sorci JJ, Paulauskis JD, Ford TE (1999) 16S rRNA restriction fragment length polymorphism analysis of bacterial diversity as a biomarker of ecological health in polluted sediments from New Bedford Harbor, Massachusetts, USA. Marine Pollution Bulletin 38:663-675

55. Stevens H, Brinkhoff T, Rink B, Vollmers J, Simon M (2007) Diversity and abundance of Gram positive bacteria in a tidal flat ecosystem. Environ Microbiol 9:1810-1822

56. Thompson JD, Higgins DG, Gibson TJ (1994) CLUSTAL W: improving the sensitivity of progressive multiple sequence alignment through sequence weighting, position-specific gap penalties and weight matrix choice. Nucleic Acids Res 22:4673-4680

57. Todorov JR, Chistoserdov AY, Aller JY (2000) Molecular analysis of microbial communities in mobile deltaic muds of Southeastern Papua New Guinea. FEMS Microbiol Ecol 33:147-155

58. Wang ZA, Cai WJ (2004) Carbon dioxide degassing and inorganic carbon export from a marsh-dominated estuary (the Duplin River): a marsh $\mathrm{CO}_{2}$ pump. Limnol Oceanogr 49:341-354

59. Weston NB, Joye SB, Porubsky WP, Erickson M, Samarkin V, MacAvoy S (2006) Pore water stoichiometry of dissolved organic matter and inorganic redox metabolites in intertidal systems. Biogeochemistry 77:375-408

60. Zmasek CM, Eddy SR (2001) ATV: display and manipulation of annotated phylogenetic trees. Bioinformatics 17:383-384 